\title{
Effects of depressive symptoms and routinization on metamemory during adulthood
}

\author{
Isabelle Tournier*, Virginie Postal \\ Laboratoire de Psychologie Santé et Qualité de vie EA 4139, Université Victor Segalen Bordeaux 2, 3 ter Place de la Victoire, 33076 Bordeaux Cedex, France
}

\section{A R T I C L E I N F O}

\section{Article history:}

Received 25 June 2009

Received in revised form 7 January 2010

Accepted 27 January 2010

Available online 5 March 2010

\section{Keywords:}

Metamemory in aging

Depressive symptoms

Routinization

\begin{abstract}
A B S T R A C T
The purpose of this study was to investigate the impact of aging, depressive symptoms and preference for routine on metamemory. Twenty-eight young adults (of mean age $=20.7$ years) and 28 older adults (68.5 years) completed the metamemory in adulthood (MIA) scale for assessing various metamemory dimensions. Compared with young adults, older adults used more external strategy. They used more internal strategy but only those with high depressive symptoms or high routinization. Older adults also reported a less efficient memory than young adults, showing less capacity and more change. In addition, depressive symptoms influenced many MIA subscales: participants with high depressive symptoms reported more external strategy use, less capacity, more change and less locus than participants with low depressive symptoms. Finally, highly routinized participants reported more use of external strategy and experienced more anxiety about memory. These results confirm the impact of aging on metamemory and show that an increase in depressive symptoms even without a depressive state and routinization also influences metamemory. This study shows the need to consider variables that modify memory perception during aging.
\end{abstract}

๑ 2010 Elsevier Ireland Ltd. All rights reserved.

\section{Introduction}

Memory complaints increase during aging and are very common among older adults. A study by Cutler and Grams (1988) showed that $40 \%$ of participants aged 55 years and over have sometimes reported trouble in remembering things. The principal interpretation of this complaint is that this is the consequence of decline in memory performances, which have regularly been reported in gerontologic studies (for a review, see: Zacks et al., 2000). However, Bolla et al. (1991) observed that memory complaints are more associated with depressed mood than memory performances. Furthermore, a measure of memory performance explained only $3 \%$ of the complaint, whereas a measure of psychological distress including depression and anxiety explained $20 \%$ of it (Smith et al., 1996). The relationship between beliefs about memory and memory performance has been found to be weak both in retrospective memory (Hertzog et al., 2000) and in prospective memory (McDonald-Miszczak et al., 1999), and more observable with naturalistic tasks than laboratory tasks (West et al., 1996). Mol et al. (2007) showed that older adults who present memory complaints also report a worse quality of life, and this relation could be mediated by depressive affects.

\footnotetext{
* Corresponding author. Tel.: +33 05575718 11; fax: +3305 56314211 . E-mail address: isabelle.tournier@etud.u-bordeaux2.fr (I. Tournier).
}

In the past, the effects of depressive state on memory performances have been shown notably on episodic memory performance. Bäckman and Forsell (1994) compared older people with and without depression and found an impaired episodic memory performance in participants with depression. However, this negative effect was more pronounced in free recall than in recognition, so depression could principally affect effortful processes in memory. Furthermore, depression could affect consolidation and recovery of information in memory (Livner et al., 2008). It might also affect the use of memory strategies, which are generally effortful as in the use of mental imagery (Hart et al., 1987; Kindermann and Brown, 1997). In the study of Bäckman and Forsell (1994), depressive participants gained less benefit than non-depressive ones from an increase in study time and the possibility of organizing words in a learning task. Similarly, research by Bäckman et al. (1996) with non-depressive participants and using a depression scale made it possible to separate participants according to their depressive symptoms, although they did not actually present a clinical state of depression. They separated depressive symptoms into motivational symptoms (lack of energy, lack of concentration, etc.) and mood symptoms ( sadness, modification of appetite, etc.). They observed that only motivational symptoms predicted memory performance by reducing the benefit of the study time increase but not by modifying the organization of items during recall or the benefit of cueing. In conclusion, depressive state and to a lesser extent 
depressive symptoms could affect the use of more efficient cognitive strategies. Depressive affects could modify beliefs and motivation associated with memory. Previous studies have shown an association between depression and anxiety (Teachman, 2006) and between depression and motivation (Bäckman et al., 1996). Moreover, depressive affects could reduce motivation and increase the anxiety associated with memory. This hypothesis is in accordance with the observation that depressive symptoms are strongly associated with memory complaints (Cargin et al., 2008).

Whereas depressive symptoms could reduce the motivation to perform an action and consequently reduce the quantity of daily activities, routinization could reduce their quality. The concept of routinization is defined as the performance of behaviors or activities in the same rhythm or way over time (Bouisson, 2002). Routines and habits are necessary to good adaptation, which is a set of behaviors responding to environmental demands and which involve the development of habits, problem solutions and the management of high anxiety (Whithbourne, 1985). Indeed, aging is associated with reduced cognitive, physical, social and psychological resources (Baltes and Lang, 1997). According to Bouisson (2002), an increase in routines can be perceived as a way of coping by protecting the elderly from the difficulties and stress associated with novel situations. However, this adaptative routinization could become maladaptative when routines become obtrusive to the point that behaviors become inflexible and to the subjects resists change. Using more and more routines could lead to reduced adaptation to novelty. This interpretation can be compared with the "disuse" perspective on cognitive aging (Salthouse, 1991) that suggests that resisting change in activities in older adults leads to the underuse of cognitive processes and skills. This effect corresponds to adage "use it or lose it", a study by Hultsch et al. (1999) showing the positive impact of investment in novel activities on cognitive aging. Animal studies have suggested that the cognitive performances of older animals are improved by exposure to complex and novel environments (Kempermann et al., 1997). Concerning older humans, intellectual activities and interest in novelty could lead to cognitive functioning being sustained (Scarmeas and Stern, 2003). In the case of routinization, there is the example of old people who perceive their memory as declining and who feel anxious about failing or being judged negatively by other people. They may decide to avoid novel situations which risk exceeding their memory capacities. Being less employed, therefore, their memory capacities will decline, as will confidence in their memory. At the same time, such individuals may minimize their social relations and thus their well-being. Bouisson (2002), Bouisson and Swendsen (2003) observed an increased preference for routinization in people aged of 65 years and more, living at home or in establishments for the elderly. Correlations showed that strong preferences for routinization are associated with high level of depression $(r=0.41$, $p<0.01)$ and anxiety $(r=0.30, p<0.01)$. Based on the 10 th and 13th year of follow-up of the Paquid epidemiological cohort study, Bergua et al. (2006) used linear regression and observed that preference for routine is associated with depression $(\beta=0.14$, $p<0.01)$ and anxiety $(\beta=0.13, p=0.01)$, but did not show an increased preference for routines during aging in older participants aged of 78 years and over. Although there was no association between the evaluation of cognitive function (MMSE) (Folstein et al., 1975) and routinization, they showed that the score reduction between MMSE of 10th and 13th year was correlated with routinization $(\beta=0.49, p<0.05$ ) after adjustment for dementia diagnosis. Furthermore they obtained a significant association between routinization and increased memory complaints $(\beta=-0.79, p<0.05)$. The authors suggested that preferences for routines reflect a response to objective and subjective losses. Dubreuil et al. (2007) investigated the relation between memory complaints and routinization, with the hypothesis that routinization could modulate the association between memory performance and memory complaints. Since total score for preferences for routines scale (Echelle des préférences de routinisation $=E P R$ ) (Bouisson, 2002) was not related to memory complaints, they did a principal component analyses and obtained two components for EPR: routinized behaviors (e.g., 'I don't like waiting at mealtimes') and non-routinized behaviors (e.g., 'I like to meet new people'). They obtained no relation between the memory complaints measure and the routinized behaviors component but there was a significant relation between memory complaints and the nonroutinized behaviors component. Accordingly, participants with a highly routinized life present fewer memory complaints, a finding explained by the fact that an environment of routines could generate fewer occasions for memory complaints. Moreover, Dubreuil et al. (2007) demonstrated that this non-routine component influences the relationship between complaint and memory performance. They hypothesized that people with strong memory complaints choose to employ more memory supports like memos or diaries and consequently live in a less memorydemanding environment and manifest fewer memory complaints. The use of memory strategies and memory complaints is part of metamemory. In fact, metamemory refers to "the knowledge one possesses about the functioning, development, use, and capacities of the human memory system in general, and one's own memory in particular" (Dixon and Hultsch, 1983).

A fundamental point in the gerontological literature is the relationship between metamemory and memory performance, and more specifically the possibility that poor metamemory explains the decline of memory during aging. While various instruments have been developed to evaluate metamemory, the metamemory in adulthood (MIA) scale (Dixon and Hultsch, 1983) is the most appealing. It contains multiple subscales of metamemory elements and presents satisfactory psychometric characteristics. Moreover, the MIA scale is one of the most widely used metamemory questionnaires and has been successfully translated into French (Boucheron, 1993). Metamemory concerns knowledge of memory functioning, beliefs and affects about memory as well as monitoring and autoregulation during memory activity (Hultsch et al., 1985, 1988). The MIA scale contains knowledge (strategy and task subscales), beliefs (capacity, change and locus subscales) and affects (anxiety and achievement subscales) about memory. In the French and German adaptations (Boucheron, 1993; Ponds and Jolles, 1996a), analyses of validation have led to dividing strategy into external strategy (e.g., memos, calendar) and internal strategy (mental imagery, words associations). The study of metamemory forms part of the work studying the associations between cognitive activities, social factors, personality and cognitive skills (Pushkar and Arbuckle, 2000; Hess, 2005). Cognitive strategies lie at the center of the relationship between metamemory and memory performance. Erroneous knowledge about tasks or the use of less efficient strategies will reduce performance. This hypothesis is in accordance with the notion that in memory tasks, the elderly use less efficient strategies (Hulicka and Grossman, 1967; Hertzog et al., 1990; Dunlosky and Hertzog, 1998). Indirectly, the belief that one's capacity and locus are diminished and having more or less motivation will affect the use of efficient cognitive strategies and consequently reduce performance. In the past, researchers studied the evolution of strategy and task subscales on the MIA. Dixon and Hultsch (1983) observed that older participants presented less knowledge of tasks but used similar strategies. Inversely, Cavanaugh and Poon (1989) observed no modification on the task subscale but showed a reduction of strategy use during aging. Finally, Ponds and Jolles (1996a) observed no modification for task during aging but showed separate subscales for external and internal strategies. They showed an increase of both in older adults. 
In summary, data on the strategy and task subscales during aging are very heterogeneous and vary according to the characteristics (level of education, activities or lifestyle) of young and older participants. Hultsch et al. (1987) noted that performance differences are more pronounced when comparing young highly educated subjects like students and older participants who have not received any formal education for many years. Moreover, attributions concerning the impact of strategies on performance vary during aging, older adults considering that memory skills influence performances more than use of strategies (BlattEisengart and Lachman, 2004). Thus many variables could modulate the use of memory strategies. In accordance with the theory of memory self-efficacy, erroneous metamemory beliefs could induce poor use of strategies. Memory self-efficacy, derived from Bandura's concept of self-efficacy (Bandura, 1997), refers to an individuals estimation of his ability to use his memory with effectiveness in various situations (Beaudoin et al., 2008). According to Hertzog et al. (1989), subscales of capacity, change and anxiety make it possible to apprehend a memory self-efficacy factor. Hertzog et al. (1987) showed that these three subscales and the locus subscale load on a dimension interpreted as memory selfefficacy. Self-efficacy judgment could influence the choice of actions, for example, the intensity and duration of effort used in a memory task. For example, older participants with strong memory self-efficacy invested more effort and time in the study of an items task than older participants with low memory self-efficacy (Berry, 1987, cited by Soederberg Miller and Lachman, 1999). Moreover, Rahhal et al. (2001) showed that older participants are less efficient than young participants only when the order emphasizes the memory aspect of the task. According to these authors, emphasizing the memory aspect of a task triggers negative stereotypes of memory performance in the elderly and thus deteriorates it. Studies (Dixon and Hultsch, 1983; Cavanaugh and Poon, 1989) have shown that the subscales of capacity, change and locus are regularly modified during aging and show a reduction of memory self-efficacy in the elderly. Whereas with young adults memory performance is associated essentially with the strategy and task subscales, older participants are more sensitive to the capacity, change and locus subscales (Dixon and Hultsch, 1983; Cavanaugh and Poon, 1989). Ponds and Jolles (1996b) observed that only the memory self-efficacy factor of the MIA scale (capacity, change and anxiety subscales) could discriminate between elderly participants with or without memory complaints. This result showed the importance of memory self-efficacy in memory functioning for elderly people, and that this could influence the motivation and confidence to engage in novel activities (Lachman et al., 1987). Consequently, metamemory could have impact on the objective and subjective quality of life (Mol et al., 2007), and various authors have claimed the importance of metamemory in the capacity to fit with environment changes and integrate memory modifications during aging (e.g., Bieman-Copland and Charness, 1994).

The perception of memory capacities could have important repercussions on well-being and investment in daily activities (Valentijn et al., 2006; Mol et al., 2007). Previous studies have shown that aging and depression can notably affect perception of memory capacities and motivation to use memory strategies. Our study explored the impact of aging, depressive symptoms without depression state and routinization on the perception of memory in general and one's own memory in particular. The metamemory concept has been used in order to gain precise knowledge on beliefs and affects concerning memory. We sought an eventual modulation of the age effect on metamemory by depressive symptoms and routinization. In spite of the exploratory nature of this research, we hypothesized an increase in strategy use for older and high routinization participants, notably for external strategies. On the other hand, strategy use would be reduced for participants with high depressive symptoms. We also hypothesized a reduction in self-efficacy for older, highly depressive and highly routinized participants.

\section{Subjects and methods}

\subsection{Participants}

Fifty-six participants (28 in each of two groups) participated in this experiment after informed consent was obtained. The young group consisted of university undergraduates between the ages of 18 and 23 years, mean $=20.7 \pm 1.6( \pm$ S.D. $)$. The old group consisted of community volunteers between the ages of 63 and 80 years $(68.5 \pm 4.6)$, recruited through the University for seniors program in Bordeaux. All participants had a score equal to or higher than 26 on the MMSE (Folstein et al., 1975) which is used to detect major cognitive deterioration. In accordance with the Center for Epidemiologic Studies of Depression Scale (CESD), participants scoring equal to or higher than 17 for men and 23 for women were excluded. All participants were native French speakers and had no history of neurological disease, psychiatric disorder or general anesthesia in the past year. Age effect for education was significant, $t_{(54)}=-3.18$, $p<0.01$, older adults having more years of education than young adults (14.4 years vs. 12.8 years). Young adults had higher scores on the MMSE than older adults (29 vs. 28.3 ), $t_{(54)}=2.13, p<0.05$.

\subsection{Procedure}

Participants completed different scale of metamemory, depression and preferences for routinization.

\subsection{Methods}

\subsubsection{The CESD}

The CESD is a self-report 20-item questionnaire which assesses the intensity of cognitive, emotional, behavior and somatic symptoms over the previous week on a 4-point Likert scale. Higher scores represent higher depressive symptoms and the original scale in English (Radloff, 1977) has a high internal consistency with alpha ranging from 0.84 to 0.90 . The French adaptation (Führer and Rouillon, 1989) conserves these properties. Hertzog et al. (1990) demonstrated the adequacy and validity of the CESD in older populations.

\subsubsection{Preferences for routines scale (EPR)}

The preferences for routines scale (Bouisson, 2002) is composed of 10 items which assess daily life habits and behaviors (e.g., sleep and meal schedules, organization of personal objects, and social exchange). A 5-point Likert scale assesses the degree of agreement with various sentences and the total score ranges from 10 to 50 , higher scores representing greater preferences for routinization. The internal consistency is acceptable with an alpha of 0.73 , the test-retest reliability is good $(r=0.84)$ and the predictive validity of actual behavioral routinization is strong (Bouisson and Swendsen, 2003).

\subsubsection{MIA scale}

The MIA (Dixon and Hultsch, 1983) is composed of 108 items measuring the memory components of knowledge, beliefs and affects. Items are completed with a 5-point Likert scale and the tool has satisfactory psychometric characteristics. The French adaptation (Boucheron, 1993) conserves these properties and is composed of 8 subscales: external strategy, internal strategy, task, capacity, change, anxiety, achievement and locus (see Table 1 for items sample). Higher scores are associated with higher use of strategy, higher knowledge of task and higher capacity, anxiety, 
Table 1

Subscales of the metamemory in adulthood.

\begin{tabular}{|c|c|c|}
\hline Subscales & Contents (example) & Item no. (max. score) \\
\hline External strategy & $\begin{array}{l}\text { Frequency of strategy external to the person (e.g., list, note). } \\
\text { «Do you write down important dates like birthdays and anniversaries?» }\end{array}$ & $9(45)$ \\
\hline Internal strategy & $\begin{array}{l}\text { Frequency of strategy involving reliance on memory internal to oneself (e.g., imagery, mental rehearsal). } \\
\text { «Do you build mental images for remembering things?» }\end{array}$ & $\begin{array}{l}9(45) \\
16(80)\end{array}$ \\
\hline Task & $\begin{array}{l}\text { Knowledge about memory tasks and processes. } \\
\text { «Most people think it easrier to remember concrete things rather than abstract notions» }\end{array}$ & \\
\hline Capacity & $\begin{array}{l}\text { Perception of own memory capacity } \\
\text { «I remember things like cooking recipes» }\end{array}$ & $17(85)$ \\
\hline Change & $\begin{array}{l}\text { Perception of change of own memory capacity } \\
\text { «My memory will get better as I get older» }\end{array}$ & $18(90)$ \\
\hline Anxiety & $\begin{array}{l}\text { Anxiety related to memory performance } \\
\text { «I would feel worried if I had to visit a new place and remember how to get back home» }\end{array}$ & $14(70)$ \\
\hline Achievement & $\begin{array}{l}\text { Perceived importance of having a good memory and performing well on memory tasks } \\
\text { "I like to remember things on my own, without having others remember them for me» }\end{array}$ & $16(80)$ \\
\hline Locus & $\begin{array}{l}\text { Perceived personal control over remembering abilities } \\
\text { «You can work on your memory as much as you like, it won't really get any better» }\end{array}$ & $9(45)$ \\
\hline
\end{tabular}

achievement and locus. On the contrary higher scores on the change subscale are associated with less change.

\section{Results}

Univariate analyses of variance were conducted to examine the effects of age, depressive symptoms and routinization on metamemory. Then analyses were conducted to study the effect of age, depressive symptoms and routinization. We were especially interested in the interaction between age and depressive symptoms and between age and routinization level. Education level, which was higher in older adults, was used as a covariable. Finally, analyses of correlations between metamemory subscales and scores of depressive symptoms and routinization were conducted.

\subsubsection{Age effect on depressive symptoms and preferences for routines}

Young adults had higher scores on depressive symptoms than older adults (13.2 vs. 9.9), $t_{(54)}=2.38, p<0.05$, but that there was no age effect on preferences for routinization (23.3 vs. 25.2), $t_{(54)}=-1.23, p>0.10$.

\subsection{Effects of aging, depressive symptoms and preferences for routinization on MIA subscales}

Data were analyzed in a $2 \times 2 \times 2$ analysis of covariance with age (young adults and older adults), depressive symptoms (low and high) and preferences for routinization (two groups: low and high) as between-subject factors. Education level was used as a covariable. Mean scores on each subscale are presented in Table 2.

External strategies were used more by older adults (33.2) than younger adults (29.7), $F(1,47)=6.01, p<0.05$, by high depressive symptom adults (33.4) than low depressive symptom adults (29.6), $F(1,47)=5.78, p<0.05$, and by high routinization adults (33.5) than low routinization adults $(29.5), F(1,47)=6.30, p<0.05$. No significant interaction was observed.

Internal strategies were more used by high routinization adults than low routinization adults (33.3 vs. 29.2 ), $F(1,47)=11.79$, $p=0.001$. The effect of age was not significant but the interaction between age and depressive symptoms was significant, $F(1,47)=8.84, p<0.01$. Post hoc comparisons showed that young adults with low depressive symptoms had a tendency to use more internal strategies than those with high depressive symptoms
Table 2

Mean scores for MIA subscales as a function of age, level of depressive symptoms and level of preferences for routines.

\begin{tabular}{|c|c|c|c|c|}
\hline & \multicolumn{4}{|c|}{ Young adults $(n=28)$} \\
\hline & \multicolumn{2}{|c|}{ Low depr. $(n=12)$} & \multicolumn{2}{|c|}{ High depr. $(n=16)$} \\
\hline & Low routin. & High routin. & Low routin. & High routin. \\
\hline Number & 6 & 6 & 9 & 7 \\
\hline External strategy & 26.7 & 32.3 & 28.2 & 31.7 \\
\hline Internal strategy & 30.3 & 37 & 32.3 & 29 \\
\hline Task & 62.3 & 68.2 & 64.9 & 62.4 \\
\hline Capacity & 63 & 62.5 & 55.7 & 57.6 \\
\hline Change & 67.8 & 55.7 & 57.3 & 64.1 \\
\hline Anxiety & 37 & 47.7 & 38.7 & 39.6 \\
\hline Achievement & 60 & 62.8 & 55.9 & 60.6 \\
\hline \multirow[t]{4}{*}{ Locus } & 33.3 & 34.7 & 32.2 & 30.8 \\
\hline & \multicolumn{4}{|c|}{ Older adults $(n=28)$} \\
\hline & \multicolumn{2}{|c|}{ Low depr. $(n=17)$} & \multicolumn{2}{|c|}{ High depr. $(n=11)$} \\
\hline & Low routin. & High routin. & Low routin. & High routin. \\
\hline Number & 8 & 9 & 6 & 5 \\
\hline External strategy & 26.7 & 32.7 & 36.3 & 37.2 \\
\hline Internal strategy & 24.6 & 32.1 & 29.7 & 35 \\
\hline Task & 62.5 & 69.1 & 59.8 & 61 \\
\hline Capacity & 60.1 & 54.1 & 43.8 & 51.4 \\
\hline Change & 52.7 & 45 & 33.8 & 45.4 \\
\hline Anxiety & 34.5 & 43.7 & 45.3 & 43.4 \\
\hline Achievement & 59.1 & 63.9 & 62.2 & 62.6 \\
\hline Locus & 32.5 & 33.1 & 28.2 & 29.8 \\
\hline
\end{tabular}

(33.7 vs. 30.7), $F(1,47)=3.34, p=0.07$, whereas older adults with low depressive symptoms used fewer internal strategies than those with high depressive symptoms ( $28.4 \mathrm{vs}$. 32.3$) F(1,47)=5.64$, $p<0.05$. Interaction between age and routinization was significant, $F(1,47)=4.05, p<0.05$. Post hoc comparisons showed that routinization did not have any effect on the utilization of internal strategies in younger adults ( $31.4 \mathrm{vs.} 33$ ), $F(1,47)=1.02, p>0.10$, whereas older adults with low routinization used fewer internal strategies than older adults with high routinization (27.1 vs. 33.5 ), $F(1,47)=14.62, p<0.001$.

Adults with low depressive symptoms had better scores on the task than those with high depressive symptoms (65.5 vs. 62), $F(1,47)=4.50, p<0.05$. None other effect was significant.

Capacities were lower for older adults than for younger adults (59.7 vs. 52.4) and for high depressive symptom adults than low 
ones (59.9 vs. 52.1), respectively $F(1,47)=4.50, p<0.05$, and $F(1,47)=8.54, p<0.01$.

Change scores were superior for young adults than for older adults (61.2 vs. 44.2), $F(1,47)=47.9, p<0.001$, and for low depressive symptoms adults than for high ones (55.3 vs. 50.2), $F(1,47)=4.94, p<0.05$.

High routinization adults had superior anxiety scores than low routinization adults (43.6 vs. 38.9 ), $F(1,47)=5.21, p<0.05$.

No significant effect was observed in the achievement.

Low depressive symptom adults had better scores on locus than high ones (33.4 vs. 30.3), $F(1,47)=6.64, p<0.05$.

Briefly, there was a significant simple age effect for subscales of external strategy, capacity and change. Older adults reported using more external strategies, having less capacity and more change (low score on change subscale) than young adults. Depressive symptoms had an impact on subscales of external strategy, task, capacity, change and locus. Adults with high depressive symptoms reported using more external strategies, had less task knowledge, less capacity, more change and less locus than low depressive symptom adults. Routinization influenced external strategies, internal strategies and anxiety subscales. Adults with high routinization reported using more external and internal strategies, and had more anxiety than low routinization adults. There was a significant interaction between age and depression on internal strategy: young adults with low depressive symptoms had a tendency to use more internal strategies than young adults with high depressive symptoms, whereas older adults with low depressive symptoms used fewer internal strategies than high depressive symptom patients. Finally, there was a significant interaction between age and routinization on internal strategy: routinization had no effect on internal strategies for younger adults whereas older adults with low routinization used fewer internal strategies than older adults with high routinization.

\subsection{Correlations between MIA subscales, CESD and EPR according to age}

The age correlations between the MIA subscales and CEDS and EPR showed that many MIA subscales were related to both CESD and EPR but only in older adults (Table 3). The effect of routinization was not combined with the depressive symptoms effect, the correlation between depressive and routinization scores being non-significant for both young and older participants (respectively, $r=0.19, p>0.10$; and $r=0.08, p>0.10$ ).

In older adults CESD was related with all MIA subscales except motivation. A high level of depressive symptoms was associated with greater use of external and internal strategies, less knowledge of tasks, less capacity, more change and anxiety and finally less locus. EPR was correlated with internal strategies and anxiety, a high level of routinization being associated with greater use of internal strategies and more anxiety.

Table 3

Correlations as a function of age between subscales of MIA and CESD and EPR.

\begin{tabular}{llllll}
\hline \multirow{2}{*}{ Subscales } & \multicolumn{2}{l}{ Young adults } & & & \multicolumn{2}{l}{ Older adults } \\
\cline { 2 - 3 } \cline { 5 - 6 } & CESD & EPR & & CESD & EPR \\
\hline External strat. & 0.09 & 0.21 & & $0.50^{* *}$ & 0.21 \\
Internal strat. & -0.05 & 0.22 & & $0.40^{*}$ & $0.51^{* *}$ \\
Task & 0.03 & 0.04 & & $-0.46^{* *}$ & 0.26 \\
Capacity & -0.27 & 0.04 & & $-0.48^{* *}$ & -0.13 \\
Change & -0.06 & -0.28 & & $-0.56^{* *}$ & -0.14 \\
Anxiety & -0.09 & 0.36 & & $0.48^{* *}$ & $0.43^{*}$ \\
Achievement & -0.25 & 0.23 & & 0.05 & 0.18 \\
Locus & 0.10 & 0.01 & & $-0.60^{* * *}$ & 0.05 \\
\hline${ }^{*} p<0.05$. & & & & \\
${ }^{* * *} p<0.01$. & & & & \\
${ }^{* * * *} p<0.001$. & & & & &
\end{tabular}

\section{Discussion}

The present study examined the impact of aging, depressive symptoms and routinization on metamemory. Metamemory corresponds to perception of the memory system in general and one's own memory in particular. In the past, research concerning this concept has essentially studied the relations between metamemory and memory performances (Cavanaugh and Poon, 1989). Nevertheless, recent studies have shown that negative metamemory can reduce engagement in cognitive and social activities (Valentijn et al., 2006), whose effects are thought to have a positive impact on cognitive ageing (Hultsch et al., 1999; Kramer and Willis, 2002; Kliegel et al., 2004). Moreover, negative perceptions of one's own memory could reduce well-being (Mol et al., 2007). Our results show that metamemory may vary with aging, depressive symptoms and routinization. Furthermore, some age changes are modulated according to depressive symptoms and routinization levels, and correlations between these two variables and metamemory were significant only in older participants.

Aging is thought to modify some metamemory dimensions (Dixon and Hultsch, 1983; Cavanaugh and Poon, 1989). In the present study, we used the Metamemory in Adulthood scale in order to measure metamemory dimensions of external and internal strategies, task, change, capacity, anxiety, achievement and locus. In accordance with Hultsch et al. (1985) these dimensions could correspond with knowledge of memory functioning, beliefs or affects about memory. Concerning knowledge about memory functioning (external strategy, internal strategy and tasks subscales), previous results concerning the use of strategies with aging are discordant. Dixon and Hultsch (1983) showed no evolution whereas Cavanaugh and Poon (1989) observed a decrease of use with age. More recently, Ponds and Jolles (1996a) distinguished external and internal strategies and reported an increase in the use of both in the elderly. In our study, we also assessed external and internal strategy use separately, and observed that only external strategies were used more by older participants than by young participants. In addition, external strategies were used more by high depressive symptom adults and by high routinization adults. External strategy use increased with aging, a finding that could be explained by the attempt to compensate the reduction of memory efficiency in older adults. Thus according to Intons-Peterson and Fournier (1986), external strategies correspond to the use of physical aid external to the person and are preferred to internal strategies because they might be more accurate and easier to use. The term of "compensation" characterizes behaviors and processes used to overcome or reduce cognitive deficits or decline (Bäckman and Dixon, 1992) and compensation mechanisms are especially relevant during normal and pathological aging. Self-reported memory compensation findings show that external strategies are more frequently reported by elderly and patients with Alzheimer disease as means of memory compensation than internal strategies (Dixon et al., 2003). Consequently, adults who have less cognitive resources such as the elderly and those with high depressive symptoms or high routinization could preferentially use external strategies. However, high routinization adults used internal strategies more than low routinization adults. In particular, interaction with age showed that this effect applied only for older adults since internal strategies were not modified with routinization in younger adults, whereas older adults with high routinization used more internal strategies than older adults with low routinization. The same observation was true for the interaction between age and depression. Whereas young adults with high depressive symptoms reported using less internal strategies than young adults with low depressive symptoms, older adults with high depressive symptoms reported using more internal strategies than subjects with low depressive symptoms. 
Results concerning depressive symptoms are surprising in comparison to previous studies having reported objective deficient use of effortful strategies (Hart et al., 1987; Kindermann and Brown, 1997). Whereas internal strategies are generally effortful, our older participants with high depressive symptoms reported use more internal strategies than those with low depressive symptoms. It may be that an increase in depressive symptoms and routinization affects the allocation of cognitive resources during aging, with notably the selection of more effortful strategies in order to cope with possible memory alterations or changes. Accurate knowledge about tasks is thought to be necessary for effective strategy selection. In accordance with several studies (Cavanaugh and Poon, 1989; Ponds and Jolles, 1996a), we did not obtain any age effect on the task subscale, young and older adults having an equivalent score. However, participants with high depressive symptoms had a lower task score than participants with low depressive symptoms. Thus depressive symptoms could modify access to knowledge about the memory task. Concerning subscales referring to beliefs (change, capacity and locus), older participants believed they had less capacity than young participants, in accordance with previous studies (Cavanaugh and Poon, 1989; Ponds and Jolles, 1996a). Capacity estimation was also reduced with high depressive symptoms. Furthermore, memory changes were perceived as greater by older than by young adults and by adults with high rather than low depressive symptoms. These results could correspond to real memory modifications or result from false perception. Indeed, a current age stereotype is that memory declines inevitably and irremediably with age, and could affect estimations of capacity and change memory in the elderly. Previous studies showed that this negative age stereotype could affect performance of memory recall (Rahhal et al., 2001; Hess et al., 2003; see Horton et al., 2008 for performance in general). The effect on depression is coherent with the negative view of themselves that depressive people have, and which includes their cognitive capacities (Kalska et al., 1999). Locus was only modified in relation to depressive symptoms, and negative distortion could again explain this difference. Concerning subscales referring to affects (anxiety and achievement), anxiety was changed only by routinization level, participants with high routinization showing more anxiety than those with low routinization. The association between an increase in routinization and an increase in memory anxiety is in accordance with this will to deal with memory anxiety. Positive correlations observed by Bouisson (2002) between routinization and anxiety measured by state-trait anxiety inventory (STAI) (Spielberger et al., 1983) were found with anxiety associated with memory. The achievement subscale was not modified by any variable.

We hypothesized an increase in strategy use, notably external strategies, in older and high routinization participants, and a reduction in high depressive symptom participants. Our hypotheses were partially verified because unexpectedly, highly depressed adults used more external strategies than low depressed ones. Results concerning internal strategy were more contrasted, revealing that an increase in depressive symptoms or routinization is associated with more internal strategy use uniquely for older participants. Memory strategies are a way to compensate memory performance (Bäckman and Dixon, 1992) and an increase in external and internal strategy use could signify the attempt to cope with memory reduction occurring with aging (Zacks et al., 2000) or depressive symptoms (Livner et al., 2008). Moreover, increased routinization could compensate the reduction of resources with aging (Bouisson, 2002), and increased strategy use could be due to the attempt to compensate memory decline. External strategy appears easier to use, more effective and more generalizable (Intons-Peterson and Fournier, 1986; Cavanaugh and Poon, 1989; Wilson and Hughes, 1997), and consequently the easiest and efficient strategies for individuals with memory impairment. Indeed, use of effective internal strategies could exceed an individuals cognitive resources. Consequently, an increase in depressive symptoms and routinization during aging could cause erroneous resource allocation. Self-efficacy could be estimated by capacity, change and anxiety subscales (Hertzog et al., 1989) and locus subscales (Hertzog et al., 1987). In accordance with our hypothesis and the literature (Dixon and Hultsch, 1983; Cavanaugh and Poon, 1989), the negative effect of age on the capacity and change subscales suggests a reduction in memory self-efficacy with age. Similarly, an increase in depressive symptoms affects memory self-efficacy, also showing a reduced capacity and an increase in change, as a reduction of locus. Thus in accordance with previous studies, depressive symptoms seem to reduce selfefficacy and to increase memory complaints irrespective of memory performances (Kalska et al., 1999). The novelty in our study is that this effect appears when the symptoms level is below the cut-off associated with a depressive state. Consequently depressive symptoms affect memory perception in spite of the absence of pathological depression. Unexpectedly, it seems that routinization has no negative influence on memory self-efficacy in spite of increased anxiety. Note that no interaction between age and depressive symptoms or routinization was found concerning metamemory beliefs and affects. These variables could be more related with older or more vulnerable elderly whereas old adults studied in our research were relatively young, in good health and well educated. Another interesting result was the fact that correlations between MIA subscales, depressive symptoms and routinization were significant only for older adults. Thus for older adults, high depressive symptoms were associated with more strategy use (external and internal strategy) and less self-efficacy memory (change, capacity and locus). Internal strategies were also used more by older adults with high routinization who also showed more anxiety.

\section{Conclusion}

These findings show the impact of aging, depressive symptoms and routinization on metamemory in older adults. Recently Kit et al. (2007) studied the relations between MIA subscales and depression in patients with traumatic brain injury. They showed that patients with mild brain trauma have a higher depression score than those without brain trauma. These subjects also showed more use of strategies and achievement, more change and less capacity than normal adults. According to Kit et al. (2007), the relationship between mild brain trauma and depression could be mediated by the strategy, capacity, change and motivation subscales. Although older adults in our study reported less depressive symptoms than young adults, we observed like Kit et al. (2007) that older adults with the highest depression scores showed more use of strategy, more change and less capacity. Contrary to mild brain trauma patients, memory modifications during aging are moderate and progressive. Moreover for these two populations, memory is very important and memory loss is associated with strong preoccupations. At present, good memory functioning in the elderly is a subject of debate. The fear of Alzheimer's disease could notably explain this preoccupation in older adults. A French survey carried out by SOFRES showed that $64 \%$ of 55-79-year-olds are highly concerned about their memory and that 45\% are worried about Alzheimer's disease (Taplin et al., 2005). Reese et al. (2000) showed that older adults have more knowledge of memory aging than younger adults, and that in both age groups, pathological memory aging is better understood than normal memory aging. These results could be explained by the fact that the elderly are more concerned about memory aging and potentially improving their memory changes associated with age. 
Some studies have shown a positive relationship between memory complaints and future cognitive decline (Jonker et al., 2000; Dik et al., 2001). Moreover, memory complaint is included in the recent concepts of mild cognitive impairment (MCI) (Petersen, 2004), which is marked by feelings of memory loss during everyday activities without any negative impact on social and working lives, and by an alteration of cognitive performances at a level between normal and pathological aging. Gallassi et al. (2008) underline the need to consider memory complaints, in the presence or not of objective memory impairment. Older adults with objective cognitive deficits could be monitored medically in order to investigate the onset or evolution of dementia, whereas older adults with a normal performance would be reassured and causes of complaints could be investigated (anxiety, depression, etc.). Metamemory is not easy to modify and is not automatically improved by memory training. However, a training program incorporating self-efficacy improves both memory performances and memory self-efficacy (West et al., 2008). Moreover, regression analyses showed that the final level of performance obtained after training was predicted notably by self-efficacy. Previous studies have indicated that older adults with high locus use more efficient strategies (Riggs et al., 1997) or have better memory performances (Cavanaugh and Poon, 1989). Consequently, inserting metamemory aspects could increase the utilization of strategies in daily life and increase awareness of the need for mnemonic training, which is generally low (Bandura, 1989). In conclusion, the present study shows metamemory modifications as a function of age, and the modulation of depressive symptoms and preference for routines. By taking metamemory into account, it becomes possible to access perceptions of memory. This could have repercussions on wellbeing, investment in social and cognitive activities and on memory performances.

\section{Conflict of interest statement}

None.

\section{Acknowledgements}

We thank the OAREIL (Office Aquitain de Recherches, d'études, d'Information, et de Liaison sur les problèmes des personnes âgées) and its director Mr. Jean-Jacques Amyot. We thank the young and older adults for their participation.

\section{References}

Bäckman, L., Dixon, R.A., 1992. Psychological compensation: a theorical framework. Psychol. Bull. 112, 259-283.

Bäckman, L., Forsell, Y., 1994. Episodic memory functioning in a community-based sample of old adults with major depression: utilization of cognitive support. J. Abnorm. Psychol. 103, 361-370.

Bäckman, L., Hill, R.D., Forsell, Y., 1996. The influence of depressive symptomatology on episodic memory functioning among clinically nondepressed older adults. J. Abnorm. Psychol. 105, 97-105.

Baltes, M.M., Lang, F.R., 1997. Everyday functioning and successful aging: the impact of resources. Psychol. Aging 12, 433-443.

Bandura, A., 1989. Regulation of cognitive processes through perceveid self-efficacy. Dev. Psychol. 25, 729-735.

Bandura, A., 1997. Self-Efficacy: The Exercise of Control. Freeman, New York.

Beaudoin, M., Agrigoroaei, S., Desrichard, O., Fournet, N., Roulin, J.-L., 2008. Validation of the French version of the memory self-efficacy questionnaire. Rev. Eur. Psychol. Appl. 58, 165-176.

Bergua, V., Fabrigoule, C., Barberger-Gateau, P., Dartigues, J.-F., Swendsen, J., Bouisson, J., 2006. Preferences for routines in older people: associations with cognitive and psychological vulnerability. Int. J. Geriatr. Psychiatry 21, 990-998.

Bieman-Copland, S., Charness, N., 1994. Memory knowledge and memory monitoring in adulthood. Psychol. Aging 9, 287-302.

Blatt-Eisengart, I., Lachman, M.E., 2004. Attributions for memory performance in adulthood: age differences and mediation effects. Aging Neuropsychol. Cogn. $11,68-79$.

Bolla, K.I., Lindgren, K.N., Bonaccorsy, C., Bleecker, M.L., 1991. Memory complaints in older adults: fact or fiction? Arch. Neurol. 48, 61-64.
Boucheron, C., 1993. Mémoire, métamémoire et vieillissement. Thèse de Doctorat, Université Nancy 2 (in French).

Bouisson, J., 2002. Routinization preferences, anxiety, and depression in an elderly French sample. J. Aging Stud. 16, 295-302.

Bouisson, J., Swendsen, J., 2003. Routinization and emotional well-being: an experience sampling investigation in an elderly French sample. J. Gerontol. B: Psychol. Sci. Soc. Sci. 58, P280-P282.

Cargin, J.W., Collie, A., Masters, C., Maruff, P., 2008. The nature of cognitive complaints in healthy older adults with and without objective memory decline. J. Clin. Exp. Neuropsychol. 30, 245-257.

Cavanaugh, J.C., Poon, L.W., 1989. Metamemorial predictors of memory performance in young and older adults. Psychol. Aging 4, 365-368.

Cutler, S.J., Grams, A.E., 1988. Correlates of self-reported everyday memory problems. J. Gerontol. 43, S82-S90.

Dik, M.G., Jonker, C., Conjus, H.C., Bouter, L.M., Twisk, J.W., Van Kamp, G.J., Deeg, D.J., 2001. Memory complaints and APOE-epsilon 4 accelerate cognitive decline in cognitively normal elderly. Neurology 57, 2217-2222.

Dixon, R.A., Hultsch, D.F., 1983. Structure and development of metamemory in adulthood. J. Gerontol. 38, 682-688.

Dixon, R.A., Hopp, G.A., Cohen, A.-L., De Frias, C.M., Bäckman, L., 2003. Self-reported memory compensation: similar patterns in Alzheimer's disease and very old adult samples. J. Clin. Exp. Neuropsychol. 25, 382-390.

Dubreuil, P., Adam, S., Bier, N., Gagnon, L., 2007. The ecological validity of traditional memory evaluation in relation with controlled memory processes and routinization. Arch. Clin. Neuropsychol. 22, 979-989.

Dunlosky, J., Hertzog, C., 1998. Aging and deficits in associative memory: what is the role of strategy production? Psychol. Aging 13, 597-607.

Folstein, M.F., Folstein, S.F., McHugh, P.R., 1975. Mini-Mental State: a pratical method for grading the cognitive state of patients for the clinician. J. Psychiatr. Res. 12, 189-198.

Führer, R., Rouillon, F., 1989. La version française de l'échelle de CES-D (Center for Epidemiological Studies-Depression Scale). Description et traduction de l'échelle d'autoévaluation. Psychiatr. Psychobiol. 4, 163-169.

Gallassi, R., Bisulli, A., Oppi, F., Poda, R., Di Felice, C., 2008. Subjective cognitive complaints, neuropsychological performance, affective and behavioral symptoms in non-demented patients. Int. J. Geriatr. Psychiatry 23, 95-101.

Hart, R.P., Kwentus, J.A., Hamer, R.M., Taylor, J.R., 1987. Selective reminding procedure in depression and dementia. Psychol. Aging 2, 111-115.

Hertzog, C., Dixon, R.A., Schulenberg, J.E., Hultsch, D.F., 1987. On the differentiation of memory beliefs from memory knowledge: the factor structure of the metamemory in adulthood scale. Exp. Aging Res. 13, 101-107.

Hertzog, C., Hultsch, D.F., Dixon, R.A., 1989. Evidence for the convergent validity of two self-report metamemory questionnaires. Dev. Psychol. 25, 687-700.

Hertzog, C., Dixon, R.A., Hultsch, D.F., 1990. Metamemory in adulthood: differentiating knowledge, belief, and behavior. In: Hess, T.M. (Ed.), Aging and Cognition: Knowledge Organization and Utilization. Oxford, England, pp. 161-212.

Hertzog, C., Park, D.C., Morell, R.W., Martin, 2000. Ask and ye shall receive: behavioral specificity in the accuracy of subjective memory complaints. Appl. Cogn. Psychol. 14, 257-275.

Hess, T.M., 2005. Memory and aging in context. Psychol. Bull. 131, 383-406.

Hess, T.M., Auman, C., Colcombe, S., Rahhal, T., 2003. The impact of stereotype threat on age differences in memory performance. J. Gerontol. B: Psychol. Sci. Soc. Sci. 58, P3-P11.

Horton, S., Baker, J., Pearce, G.W., Deakin, J.M., 2008. On the malleability of performance. Implications for seniors. J. Appl. Gerontol. 27, 446-465.

Hulicka, I.M., Grossman, J., 1967. Age group comparisons for the use of mediators in paired associate learning. J. Gerontol. 22, 46-61.

Hultsch, D., Dixon, R.A., Hertzog, C., 1985. Memory perceptions and memory performance in adulthood and aging. Can. J. Aging 4, 179-187.

Hultsch, D., Hertzog, C., Dixon, R.A., 1987. Age differences in metamemory: resolving the inconsistencies. Can. J. Psychol. 41, 193-208.

Hultsch, D., Hertzog, C., Dixon, R.A., Davidson, H., 1988. Memory self-knowledge and self-efficacy in the aged. In: Howe, M.L., Brainerd, C.J. (Eds.), Cognitive Development in Adulthood: Progress in Cognitive Development Research. Springer Verlag, New York, pp. 65-92.

Hultsch, D., Hertzog, C., Small, B.J., Dixon, R.A., 1999. Use it or lose it: engaged lifestyle as a buffer of cognitive decline in aging? Psychol. Aging 14, 245-263.

Intons-Peterson, M.J., Fournier, J., 1986. External and internal memory aids: when and how often do we use them? J. Exp. Psychol.: Gen. 115, 267-280.

Jonker, C., Geerlings, M.I., Schmand, B., 2000. Are memory complaints predictive for dementia? A review of clinical and population-based studies. Int. J. Geriatr Psychiatry 15, 983-991.

Kalska, H., Punamäki, R.-L., Mäkinen-Pelli, T., Saarinen, M., 1999. Memory and metamemory functioning among depressed patients. Appl. Neuropsychol. 6 96-107.

Kempermann, G., Kuhn, H.G., Gage, F.H., 1997. More hippocampus neurons in adult mice living in an enriched environment. Nature 386, 493-495.

Kindermann, S.S., Brown, G.G., 1997. Depression and memory in the elderly: a metaanalysis. J. Clin. Exp. Neuropsychol. 5, 625-642.

Kit, K.A., Mateer, C.A., Graves, R.E., 2007. The influence of memory beliefs in individuals with traumatic brain injury. Rehabil. Psychol. 52, 25-32.

Kliegel, M., Zimprich, D., Rott, C., 2004. Life-long intellectual activities mediate the predictive effect of early education on cognitive impairment in centenarians: a retrospective study. Aging Ment. Health 8, 430-437.

Kramer, A.F., Willis, S.L., 2002. Enhancing the cognitive vitality of older adults. Psychol. Sci. 11, 173-177. 
Lachman, M.E., Steinberg, E., Trotter, S., 1987. Effects of control beliefs and attributions on memory self-assessments and performance. Psychol. Aging 2, 266-271.

Livner, A., Berger, A.-K., Karlsson, S., Bäckman, L., 2008. Differential effects of depressive symptoms on prospective and retrospective memory in old age. J. Clin. Exp. Neuropsychol. 30, 272-279.

McDonald-Miszczak, L., Gould, O.N., Tychynski, D., 1999. Metamemory predictors of prospective and retrospective memory performance. J. Gen. Psychol. 126, 37-52.

Mol, M., Carpay, M., Ramakers, I., Rozendaal, N., Verhey, F., Jolles, J., 2007. The effect of perceived forgetfulness on quality of life in older adults; a qualitative review. Int. J. Geriatr. Psychiatry 22, 393-400.

Petersen, R.C., 2004. Mild cognitive impairment as a diagnostic entity. J. Inter. Med. 256, 183-194.

Ponds, R.W.H.M., Jolles, J., 1996a. The abridged Dutch metamemory in adulthood (MIA) questionnaire: structure and effects of age, sex, and education. Psychol. Aging 11, 324-332.

Ponds, R.W.H.M., Jolles, J., 1996b. Memory complaints in elderly people: the role of memory abilities, metamemory, depression, and personality. Educ. Gerontol. 22, 341-357.

Pushkar, D., Arbuckle, T., 2000. Le contexte général du vieillissement: processus affectifs, sociaux et cognitifs. In: Cappeliez, P., Landreville, P., Vézina, J. (Eds.), Psychologie clinique de la personne âgée. Masson, Paris, (in French), pp. $1-22$.

Radloff, L.S., 1977. The CES-D Scale: a self-report depression scale for research in the general population. Appl. Psychol. Meas. 3, 385-401.

Rahhal, T.A., Hasher, L., Colcombe, S.J., 2001. Instructional manipulations and age differences in memory: now you seem them, now you don't. Psychol. Aging 16 , 697-706.

Reese, C.M., Cherry, K.E., Copeland, A.L., 2000. Knowledge of normal versus pathological memory aging in younger and older adults. Aging Neuropsychol. Cogn. 7 $1-8$.

Riggs, K.M., Lachman, M.E., Wingfield, A., 1997. Taking charge of remembering: locus of control and older adults' memory for speech. Exp. Aging Res. 23, 237-256.
Salthouse, T.A., 1991. Theoretical Perspectives on Cognitive Aging. Lawrence Erlbaum Associates, Hillsdale.

Scarmeas, N., Stern, Y., 2003. Cognitive reserve and lifestyle. J. Clin. Exp. Neuropsychol. 25, 625-634.

Smith, G.E., Petersen, R.C., Ivnik, R.J., Malec, J.F., Tangalos, E.G., 1996. Subjective memory complaints, psychological distress, and longitudinal change in objective memory performance. Psychol. Aging 11, 272-279.

Soederberg Miller, L.M., Lachman, M.E., 1999. The sense of control and cognitive aging: toward a model of mediational processes. In: Hess, T.M., BlanchardFields, F. (Eds.), Social Cognition and Aging. Academic Press, San Diego, pp. 281-304.

Spielberger, C.D., Gorsuch, R.R., Lushene, R.E., 1983. Manual for the State-Trait Anxiety Inventory (STAI). Consulting Psychologists Press, Palo Alto.

Taplin, J.M., Péruchon, M., Charazac, P., Joubert, C., Brouillet, D., Martin, S., Chevance, A., 2005. Cinq paradigmes cliniques du vieillissement. Dunod, Paris (in French).

Teachman, B.A., 2006. Aging and negative affect: the rise and fall and rise of anxiety and depression symptoms. Psychol. Aging 21, 201-207.

Valentijn, S.A., Hill, R.D., Van Hooren, S.A.H., Bosma, H., Van Boxtel, M.P.J., Jolles, J., Ponds, R.W.H.M., 2006. Memory self-efficacy predicts memory performance: results from a 6-year follow-up study. Psychol. Aging 21, 165-172.

West, R.L., Dennehey-Basile, D., Morris, M.P., 1996. Memory self-evaluation: the effects of age and experience. Aging Neuropsychol. Cogn. 3, 67-83.

West, R.L., Bagwell, D.K., Dark-Freudeman, A., 2008. Self-efficacy and memory aging: the impact of a memory intervention based on self-efficacy. Aging Neuropsychol. Cogn. 15, 302-329.

Whithbourne, S.K., 1985. The Me I Know: A Study of Adult Identity. Springer, New York.

Wilson, B.A., Hughes, J.C.E., 1997. Coping with amnesia: the natural history of a compensatory memory system. Neuropsychol. Rehabil. 7, 43-56.

Zacks, R.T., Hasher, L., Li, K.Z.H., 2000. Human memory. In: Craik, F.I.M., Salthouse, T.A. (Eds.), The Handbook of Aging and Cognition. second ed. Lawrence Erlbaum Associates Publishers, Mahwah, pp. 293-357. 